Research Article

\title{
Investigation of Energy and Damage Evolutions in Rock Specimens with Large-Scale Inclined Prefabricated Cracks by Uniaxial Compression Test and AE Monitoring
}

\author{
Xiaolou Chi $\mathbb{D}^{1,2,3,4}$ Ke Yang $\mathbb{D}^{1,2,3,4,5}$ and Zhen Wei $\mathbb{D}^{1,2,3,4}$ \\ ${ }^{1}$ State Key Laboratory of Mining Response and Disaster Prevention and Control in Deep Coal Mines, \\ Anhui University of Science and Technology, Huainan 232001, Anhui, China \\ ${ }^{2}$ Key Laboratory of Mining Coal Safety and Efficiently Constructed by Anhui Province and Ministry of Education, \\ Anhui University of Science and Technology, Huainan 232001, Anhui, China \\ ${ }^{3}$ National \& Local Joint Engineering Research Center of Precision Coal Mining, Anhui University of Science and Technology, \\ Huainan 232001, Anhui, China \\ ${ }^{4}$ School of Energy and Safety, Anhui University of Science and Technology, Huainan 232001, Anhui, China \\ ${ }^{5}$ Institute of Energy, Hefei Comprehensive National Science Center, Hefei 230031, Anhui, China \\ Correspondence should be addressed to Xiaolou Chi; chixiaolou@163.com
}

Received 20 June 2020; Revised 15 August 2020; Accepted 23 August 2020; Published 7 September 2020

Academic Editor: Bisheng Wu

Copyright ( $\odot 2020$ Xiaolou Chi et al. This is an open access article distributed under the Creative Commons Attribution License, which permits unrestricted use, distribution, and reproduction in any medium, provided the original work is properly cited.

\begin{abstract}
To explore the energy dissipation mechanism and damage evolution characteristics of rock specimens under compressive loading, we performed the acoustic emission (AE) testing under uniaxial compression in intact rock specimens and those with large-scale prefabricated cracks. The basic mechanical properties of both types of specimens were analyzed comprehensively, and the evolution patterns of strain energy indicators (total strain, elastic, and dissipative energies) in rock specimens before the peak on the stress-strain curve were identified. We further revealed the effect of the prefabricated crack dip angle, which controlled the surplus energy conversion of the following peak deformation and failure in the rock specimens. Using the modified equation of rock specimen damage evolution characterized by the AE energy and examining the fracture surface morphology via the scanning electron microscopy (SEM), the AE distribution law for rock specimen damage was revealed. An increase in the prefabricated crack dip angle was shown to reduce the peak stress and strain of rock specimens, which experienced a transition from the tensile and splitting failure mode to shear and slip one. Cracked rock specimens exhibited strain energy accumulation at the elastic deformation stage of the stress-strain diagram and rapid energy consumption at the plastic stage. By contrast, the intact rock specimens had a smoother energy evolution pattern. As the prefabricated crack dip angle increased, the dissipated and surplus strain energies' shares increased. Moreover, the first peak of the AE energy occurred earlier, and the stress needed for its occurrence decreased as the dip angle increased. According to the damage evolution equation for rock specimens, their damage process can be subdivided into the initial damage, stable damage increase, and the accelerating damage increase stages. An increase in the prefabricated crack dip angle accelerated the damage accumulation in rock specimens. The locking effect of the sawtooth-like structures on the fracture surface was less conspicuous, and the fracture surface roughness increased. Thus, microcracks gradually developed, and rock specimens became more susceptible to sudden unstable failure.
\end{abstract}

\section{Introduction}

Coal mining involves roadway tunneling and stoping of working face, which usually leads to the exposure of such macroscopic geological structures as faults and joints. These structures are sources of crack initiation and propagation, in which processes jeopardize the mining production safety and require in-depth analysis. In particular, multiple studies of these phenomena have been reported in China, where coal is considered the primary source of energy in the foreseeable 
future $[1,2]$. Thus, Yang et al. [3, 4] studied the crack propagation and penetration mechanisms in rock specimens with prefabricated single and double cracks while Li et al. [5] characterized the mechanical properties of precracked rock specimens under uniaxial compression. Although both studies yielded essential findings on the respective governing laws, they covered mainly small-scale lengths and dip angles of prefabricated cracks in rock specimens. In contrast, in engineering practice, the scale and occurrence of macroscopic geological structures in the rock mass have a considerable impact on the degree of fragmentation and the possibility of dynamic disasters. Taking rock joints as a research object, Xue et al. [6] investigated the mechanism by which the fault scale influenced the dislocation movement of faults after activation. Yu et al. [7] analyzed two possible pathways whereby the dip angle of faults influenced the fault activation, which was found to be accompanied by energy accumulation and dissipation. The energy parameters as core indicators of dynamic disasters, including rockburst, were adopted in several studies [8-11]. Given the above, the identification of the energy evolution laws governing the damage and failure processes in rock specimens with largescale prefabricated cracks with various dip angles is very topical.

Zhao et al. [12] experimentally studied the energy dissipation mechanism of rock specimens subjected to uniaxial compression. Zhang et al. [13] analyzed energy variation in rock specimens under the triaxial compression test conditions. Yang et al. [14] revealed the energy evolution mechanism and failure law during the loading and unloading of specimens produced by combining coal and rock mass. Wang et al. [15] reported the rock specimens' energy conversion features with nonpenetrating joints. The above studies provide a systematic analysis of the total strain, elastic, and dissipative energy components figuring in the stress-strain relationship of intact rock specimens, coal-rock mass combinations, and rock specimens with small-scale prefabricated cracks. However, the presence of macroscopic defects with increasing scales and dip angles in rock specimens increases the probability of their dynamic (impact) failure. In such cases, the surplus energy causing dynamic failure becomes a nonnegligible factor.

Besides the energy input and dissipation observed during the loading of rock specimens, their damage occurs continuously. The damage accumulation finally induces the overall failure of the rock specimen. There are many ways to define the damage variable of rock specimens [16]. Some scholars based their definitions on the elastic modulus [17] or plastic strain [18] values. However, at the compaction stage of the stress-strain relationship, the elastic modulus of a rock specimen increases. Therefore, if the damage variable is defined by the elastic modulus, a descending trend will be predicted, that is, the occurrence of "negative damage" [19]. Moreover, at the compaction stage, the strain changes rapidly, and the rock specimen damage is supposed to be small. Thus, neither the elastic modulus nor plastic strain can accurately reflect the rock specimen's damage process. Deformation and failure of the rock specimen under loading are the results of damage driven by energy. It is reasonable to define the rock specimen's damage variable from the strain energy perspective [20]. Liu et al. [21] described the damage variable by the share of dissipative energy in the total strain energy. However, this definition was susceptible to the influence of the stiffness of the test machine and brittleness of the rock specimen. As a result, the realistic constitutive deformation could hardly be obtained. In recent years, acoustic emission (AE) testing has been increasingly applied to rock mechanics. The AE energy is highly sensitive to rock specimen damage and fracture, and this feature has been utilized to characterize the rock specimen damage [22]. However, rock specimens may retain residual strength either under uniaxial or triaxial compression. Therefore, it is necessary to refine the equation of rock specimen damage evolution characterized by the AE energy to estimate the damage evolution process under loading.

In the present study, intact rock specimens and those with large-scale prefabricated cracks were taken as the research objects. The uniaxial compression tests and $\mathrm{AE}$ monitoring were performed to analyze the prepeak total strain, elastic, and dissipative energy components during the stress-strain evolution. Evolutions of postpeak released energy and surplus energy under different prefabricated crack dip angles were also monitored and analyzed. The equation of rock specimen damage evolution characterized by the AE energy parameters was refined. SEM was employed to analyze the damage features of the intact and precracked rock specimens. The research findings provide theoretical guidance for disaster prevention and control of mining production safety.

\section{Experimental}

2.1. Rock Specimen Preparation. All rock specimens used in the experiments were collected from the fine sand strata in the roof of the 11513 working face of the Panbei Coal Mine located in Huainan city, Anhui Province of China. The largescale rock specimens collected on-site were processed into standard cylindrical rock specimens with a diameter of $50 \mathrm{~mm}$ and a height of $100 \mathrm{~mm}$ by using laboratory rock core drill, rock cutter, and grinding machine. The unevenness at both end faces of rock specimens did not exceed $0.05 \mathrm{~mm}$. A total of twelve standard rock specimens were prepared and divided into four groups. Group 1 consisted of three intact rock specimens $\left(R_{1}, R_{2}\right.$, and $\left.R_{3}\right)$ while each of the remaining three groups contained three precracked rock specimens with crack dip angles of 30,45 , and $60^{\circ}$, respectively. The precrack dip angle was the included angle between the crack line and the end surface of the rock specimen. The precracks were made by cutting with a diamond-tipped cutter. The rock specimens in group 2 were numbered as $30^{\circ}-R_{1}, 30^{\circ}-R_{2}$, and $30^{\circ}-R_{3}$, respectively. The same intuitive numbering principle was used for specimens in groups 3 and 4 . The rock specimen preparation results are depicted in Figure 1.

2.2. Experimental Setup. The experimental setup included the loading control system, AE monitoring system, digital monitoring system, and SEM monitoring system, as shown 


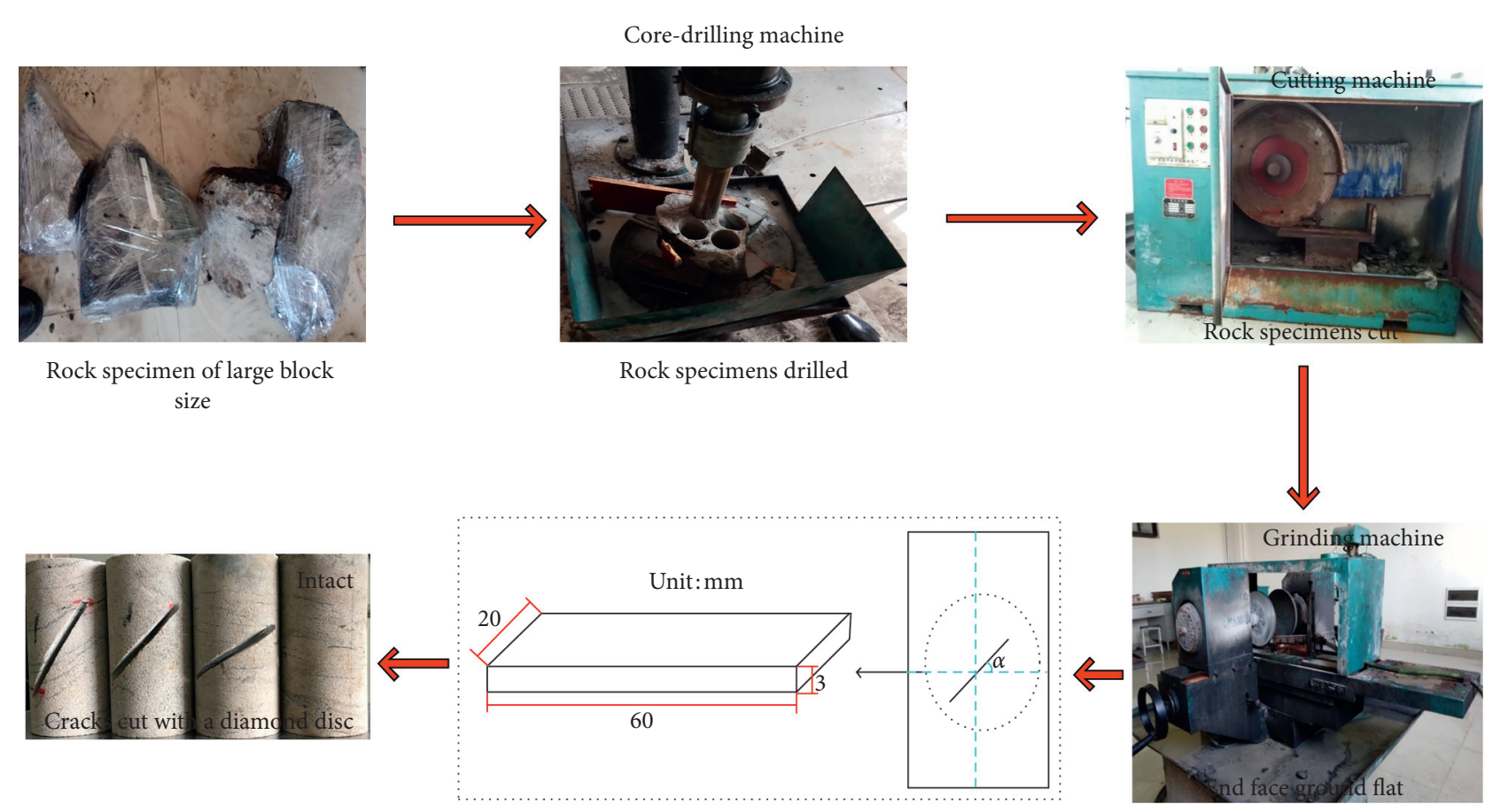

Figure 1: Rock specimen's processing and preparation.

in Figure 2. During the testing, the first three systems were launched simultaneously to facilitate subsequent data processing while the SEM monitoring system was used after tests to scan the macroscopic fracture surfaces in the intact and precracked rock specimens and to assess the microscopic damage features.

The loading control system used an RMT-150B multifunction automatic rigid rock material testing servo machine. This system could realize conventional uniaxial and triaxial compression test modes, along with automated data collection, processing, and display of the stress-strain curve. The load was increased at the loading rate of $0.5 \mathrm{kN} / \mathrm{s}$ until the final fracture of rock specimens.

A DS5-16B multichannel full-wave AE signal analyzer was equipped for the $\mathrm{AE}$ monitoring system. This system could extract such characteristic parameters as AE energy and ringdown count. Four AE transducers were installed, and the coupling agent was applied between the AE transducers and the rock specimens. Before the tests, the system calibration was performed several times to adjust its accuracy. Finally, the AE transducers' resonance frequency of $100-600 \mathrm{kHz}$, sampling rate of $3 \mathrm{MHz}$, preamplifier gain of $40 \mathrm{~dB}$, and monitoring threshold value of $35 \mathrm{~dB}$ were preset.

A FlexSEM1000 scanning electron microscope, which could achieve a $60-300 \mathrm{~K}$ magnification and a $0.3-20 \mathrm{kV}$ accelerating voltage, with a resolution of $4 \mathrm{~nm}$, was applied in SEM examinations. A Nikon camera was provided for the digital monitoring system to capture the fracture morphology during the loading process.

2.3. Strain-Stress Relationship in Rock Specimens. Using the RMT-150B rock testing machine, stress-strain curves of the intact and precracked rock specimens were monitored and constructed during the loading process. For brevity sake, only four stress-strain curves of typical intact and precracked rock specimens are shown in Figure 3.

As shown in the figure, stress-strain curves of typical intact and precracked rock specimens exhibited similar variation patterns. All of them underwent the compaction stage, elastic stage, plastic stage, and residual deformation stage. As the prefabricated crack dip angle increased, the peak strength and strain of rock specimens decreased. The stress-strain curves of the intact and precracked rock specimens presented the left-shifting and compression trend. This can be attributed to the fact that the prefabricated cracks were large-scale, which affected the structural integrity of rock specimens and increased the initial damage. As the prefabricated crack dip angle increased, the axial stress component acting on the rock specimens along the dip of the prefabricated cracks increased. Under the action of the intense shear stress at the crack tip, the original cracks propagated while new ones were formed as well, thus leading to the overall failure of rock specimens. As a result, the rock specimens' peak strength and strain decreased, leading to a progressive aggravation of their brittle fracture on the macroscopic scale.

\section{Mechanism of Energy Evolution in Rock Specimens}

3.1. Theoretical Background. Taking a typical intact rock specimen as an example, the assessment of prepeak and postpeak strain energies can be based on the calculation principle illustrated by Figure 4(a). 


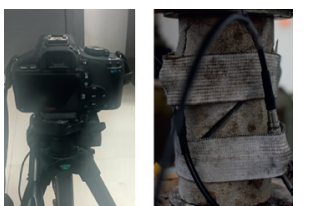

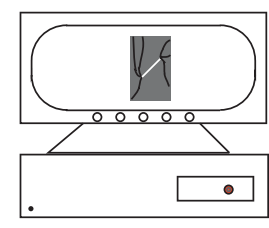

Digital photography system

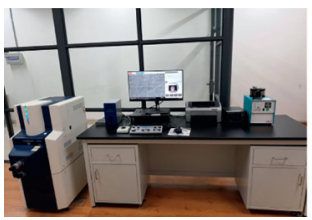
SEM system

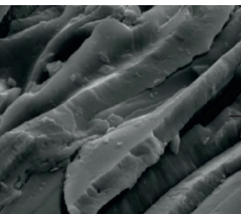

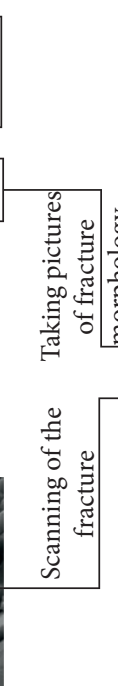

FIGURE 2: Loading and monitoring system.

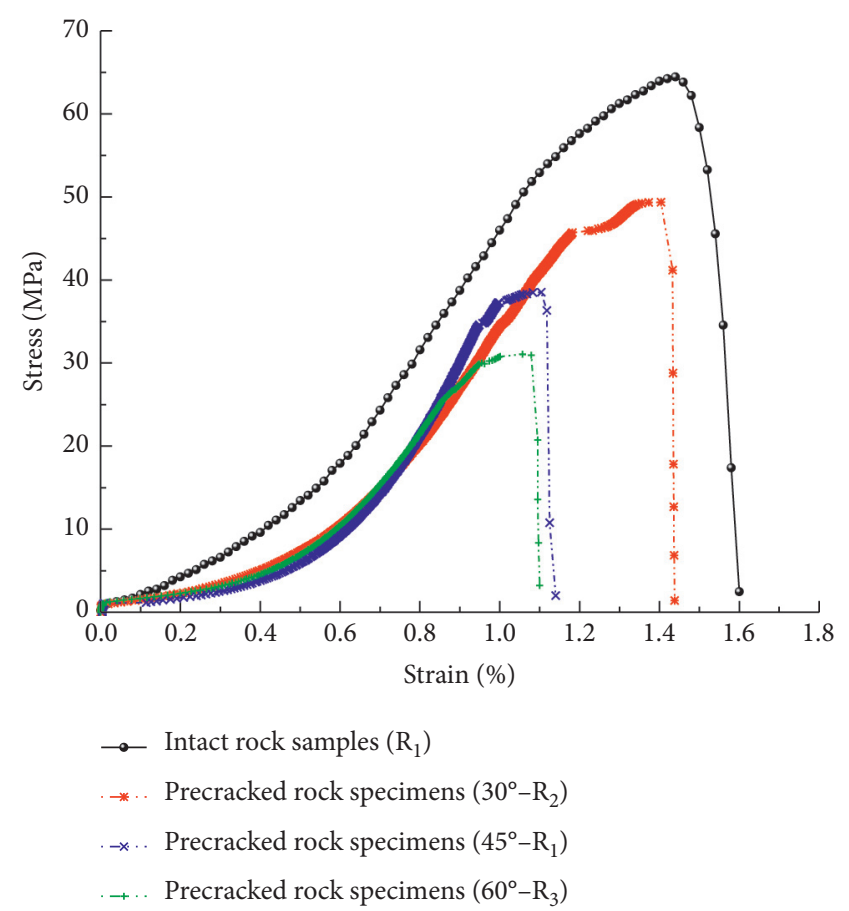

Figure 3: Stress-strain curves of typical intact and precracked rock specimens.

It is assumed that the energy conversion between the RMT-150B rock testing machine and rock specimens does not involve heat exchange with the environment. Then, according to the first law of thermodynamics [23],

$$
U_{\mathrm{o}}=U_{\mathrm{e}}+U_{\mathrm{d}},
$$

where $U_{\mathrm{o}}, U_{\mathrm{e}}$, and $U_{\mathrm{d}}$ are the prepeak total strain, elastic, and dissipative energies, respectively, of the rock specimen during the loading process, $\mathrm{J} / \mathrm{m}^{3}$.
The averages of $\sigma_{\mathrm{i}}$ and $\sigma_{\mathrm{i}+1}$ corresponding to the calculus interval $\mathrm{d} \varepsilon$ are taken. From the lower and upper bounds of calculus 0 and $\varepsilon_{1}$ [24], $U_{\mathrm{o}}$ is given by

$$
U_{\mathrm{o}}=\int_{0}^{\varepsilon_{1}} \frac{\sigma_{i}+\sigma_{i+1}}{2} \mathrm{~d} \varepsilon,
$$

where $\sigma_{\mathrm{i}}$ is the stress at any point of the stress-strain curve, $\mathrm{MPa}$, and $\varepsilon_{1}$ is the strain corresponding to the peak strain, \%.

According to the curve of one loading-unloading cycle of the uniaxial compression test, the prepeak unloading path is consistent with the loading curve slope. According to Hooke's law $[25,26], U_{\mathrm{e}}$ is given by

$$
U_{\mathrm{e}}=\frac{1}{2} \sigma_{\mathrm{c}} \varepsilon_{\mathrm{e}} \approx \frac{\sigma_{i}^{2}}{2 E_{0}},
$$

where $\sigma_{\mathrm{c}}$ is the peak strength, MPa; $\varepsilon_{\mathrm{e}}$ is the prepeak elastic strain, \%; and $E_{0}$ is the initial elastic modulus, $\mathrm{MPa}$.

The prepeak total energy consists of the elastic $U_{\mathrm{e}}$ and dissipative $U_{\mathrm{d}}$ energies [24]; thus, $U_{\mathrm{d}}$ is given by

$$
U_{\mathrm{d}}=U_{\mathrm{o}}-U_{\mathrm{e}}=\int_{0}^{\varepsilon_{1}} \frac{\sigma_{i}+\sigma_{i+1}}{2} \mathrm{~d} \varepsilon-\frac{1}{2} \sigma_{\mathrm{c}} \varepsilon_{\mathrm{e}} .
$$

The postpeak released energy $U_{\mathrm{f}}$ is the envelope area from $\varepsilon_{1}$ to $\varepsilon_{2}$ [27], and $U_{\mathrm{f}}$ is given by

$$
U_{\mathrm{f}}=\int_{\varepsilon_{1}}^{\varepsilon_{2}} \frac{\sigma_{i}+\sigma_{i+1}}{2} \mathrm{~d} \varepsilon,
$$

where $\varepsilon_{2}$ is the peak strain, \%.

Some part of the prepeak elastic energy $U_{\mathrm{e}}$ is converted into the postpeak released energy $U_{\mathrm{f}}$, while the remaining part is converted into surplus energy $U_{\mathrm{y}}$. The latter is derived as follows:

$$
U_{\mathrm{y}}=U_{\mathrm{e}}-U_{\mathrm{f}}=\frac{1}{2} \sigma_{\mathrm{c}} \varepsilon_{\mathrm{e}}-\int_{\varepsilon_{1}}^{\varepsilon_{2}} \frac{\sigma_{\mathrm{i}}+\sigma_{\mathrm{i}+1}}{2} \mathrm{~d} \varepsilon
$$




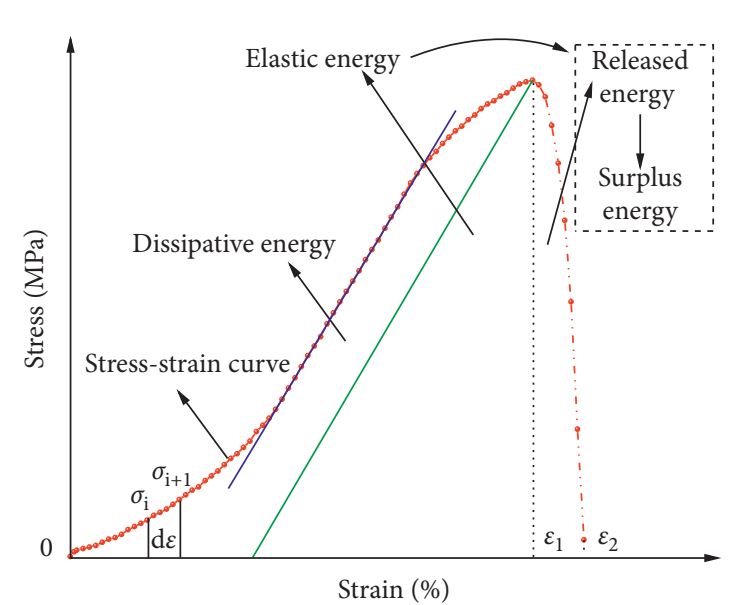

(a)

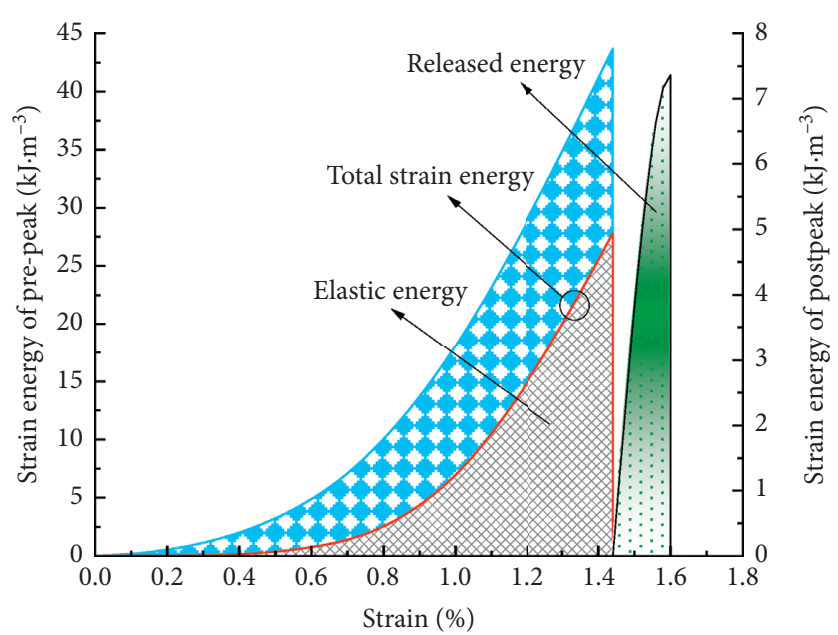

(b)

FIGURE 4: The energy conversion process of typical intact rock specimens: (a) strain energy calculation principle and (b) strain energy area.

The surplus energy can be converted into kinetic energy for rock ejection, inducing dynamic disasters. Based on the above calculation idea, the prepeak (total strain, elastic, and dissipative) energies, as well as postpeak (released and surplus) energies in typical intact rock specimens, were derived, as shown in Figure 4(b).

\subsection{Energy Conversion Characteristics of the Prepeak Strain} Energy. Figure 5 depicts the relationship between the stress, prepeak strain energy, and strain in the typical intact and precracked rock specimens. It can be observed that the deformation and failure of rock specimens under loading reflect the energy evolution from the input energy from the test machine to the elastic energy accumulation in rock specimens and finally to the dissipative energy release. Energy-driven rock specimens underwent damage until macroscopic instability and failure. The total strain energy of intact and precracked rock specimens increased continuously. The elastic energy curve showed a similar trend to the stress-strain one. The dissipative energy in intact rock specimens increased gradually while that in precracked rock specimens first increased gradually and then dropped significantly, followed by a rapid rise.

At each prepeak stage of the stress-strain curve, intact and precracked rock specimens also had similar variations in the prepeak strain energy components.

(A) Compaction stage: The dissipative energy in intact and precracked rock specimens increased nonlinearly as the rock specimen deformation was aggravated. Its value was higher than the elastic energy of rock specimens because the original cracks in rock specimens developed, consuming the absorbed energy.

(B) Elastic stage: As the original cracks closed, the elastic energy of the intact and precracked rock specimens gradually increased. After the elastic energy curve intersected with the dissipative energy curve (i.e., their values become equal), the elastic energy of precracked rock specimens increased at an accelerating rate. In contrast, the dissipative energy curve showed an inflection point for the downward trend. In intact rock specimens, both the elastic and dissipative energies increased stably. The reason was that the prefabricated cracks changed the initially uniform bulk stress state of rock specimens. The tips of the prefabricated cracks were more likely to store elastic energy, leading to the stress concentration phenomenon. Besides, at this stage, the total strain energy increased at a constant rate, and the dissipative energy decreased.

(C) Plastic stage: When the elastic energy accumulating at the prefabricated crack tips was larger than the surface free energy needed for crack development, the original cracks propagated. In the meantime, new cracks were formed, and an inflection point for an upward trend appeared on the dissipative energy curve. As the original and new cracks continued to propagate at the prefabricated crack tips, the elastic energy stored in rock specimens was consumed, leading to a sudden dissipative energy jump.

3.3. The Precrack Dip Angle Effect on the Peak Strain Energy. Figure 6(a) shows the relationship between the peak strain energy and precrack dip angle in typical intact and precracked rock specimens. The spheres indicate the peak values of prepeak total strain energy along the $y$-axis. The spheres' size indicates the peak value of the prepeak elastic energy while their color indicates the peak value of the prepeak dissipative energy. It can be seen that as the precrack dip angle increased, all peak values of strain energy decreased. The peak values of the total strain energy were $43.68,30.07,21.99$, and $13.39 \mathrm{~kJ} \cdot \mathrm{m}^{-3}$, respectively. Their reduction rates were $31.16,26.87$, and $39.11 \%$, respectively. As the precrack dip angle increased, prepeak total strain energy peak values increased as well. The peak 


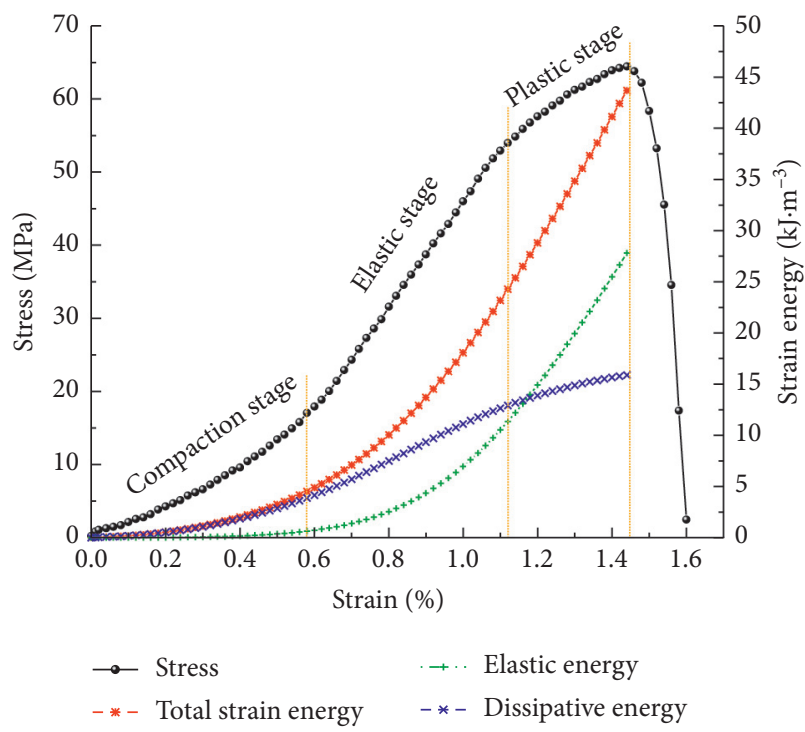

(a)

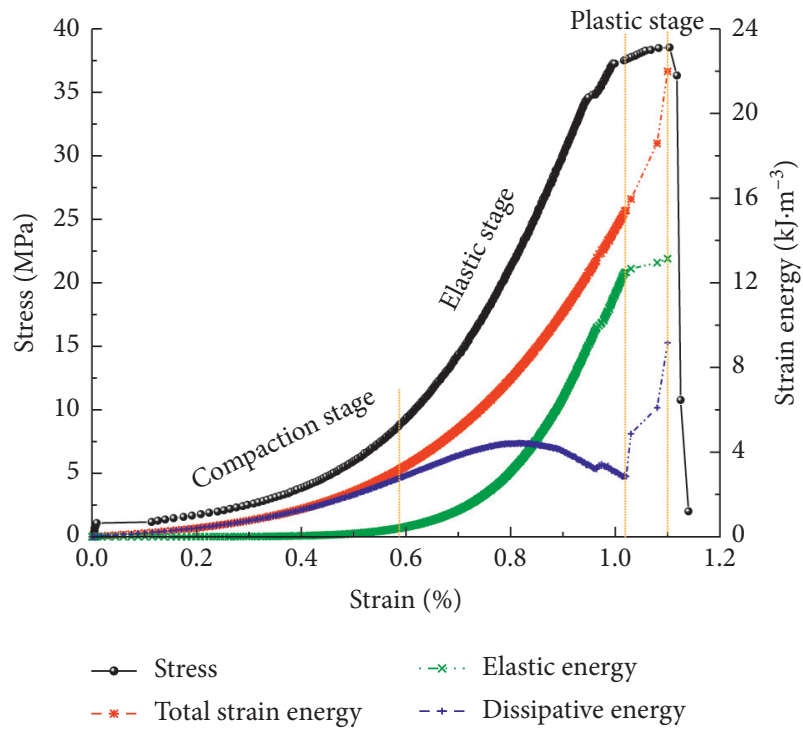

(c)

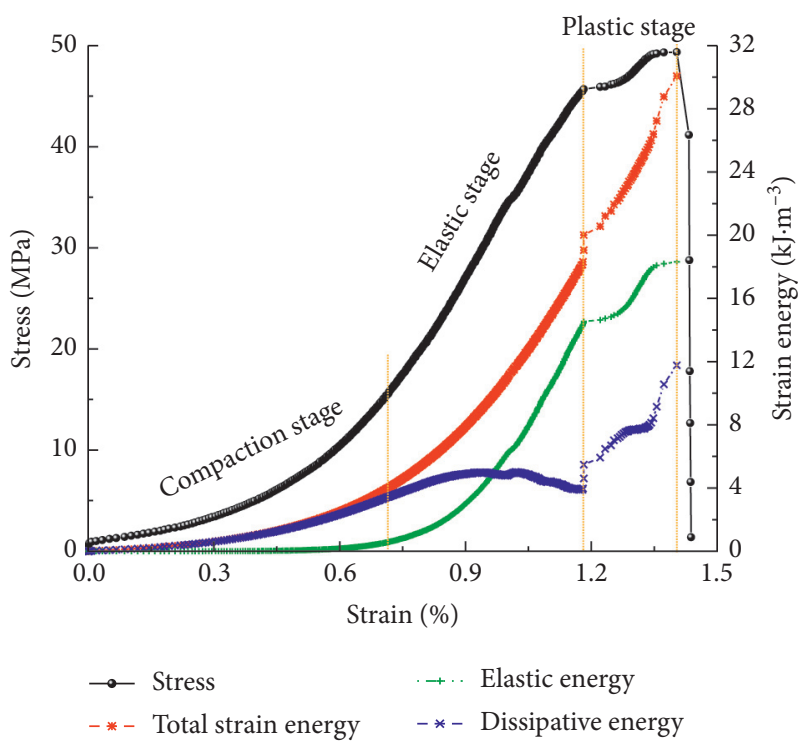

(b)

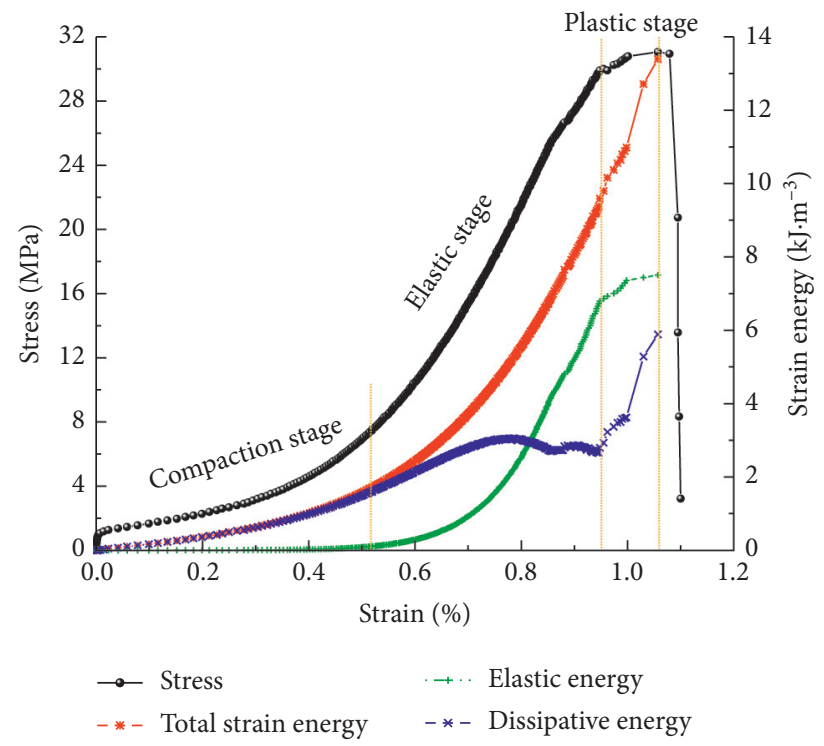

(d)

Figure 5: The relationships between stress, prepeak strain energy, and strain in typical intact (a) and precracked rock specimens with crack angles of $30^{\circ}(\mathrm{b}), 45^{\circ}(\mathrm{c})$, and $60^{\circ}(\mathrm{d})$.

values of prepeak elastic energy were $27.81,18.31,13.14$, and $7.51 \mathrm{~kJ} \cdot \mathrm{m}^{-3}$, respectively. The reduction rates were $34.16,28.24$, and $42.84 \%$, respectively, being comparable to those of prepeak total strain energy's peak values. The above results indicated that the precrack dip angle had a significant impact on the rock specimens' peak strain energy. As it was already mentioned, precrack tips were more likely to store elastic energy, leading to the stress concentration phenomenon. As the precrack dip angle increased, the degree of shear stress concentration along the precrack tip increased in rock specimens under the same axial loading. Moreover, the prefabricated cracks were of a larger scale, leading to a more severe initial damage. New tips were formed and developed at the precrack tips, which finally resulted in a decrease in the elastic energy stored in the rock specimens. Consequently, the peak total strain energy gradually dropped.

Figure 6(b) shows the relationship between the share of peak strain energy and the precrack dip angle in typical intact and precracked rock specimens. It can be seen that the peak strain energy shares before the peak in rock specimens with different precrack dip angles were 63.44, 61.02, 57.30, and $54.03 \%$, respectively. The prepeak dissipative strain energy shares in rock specimens with different precrack dip angles were $36.54,38.96,42.85$, and $45.97 \%$. Thus, the peak elastic energy share before the peak significantly exceeded that of the peak dissipative energy. This strongly indicates that the total strain energy input in rock specimens before 


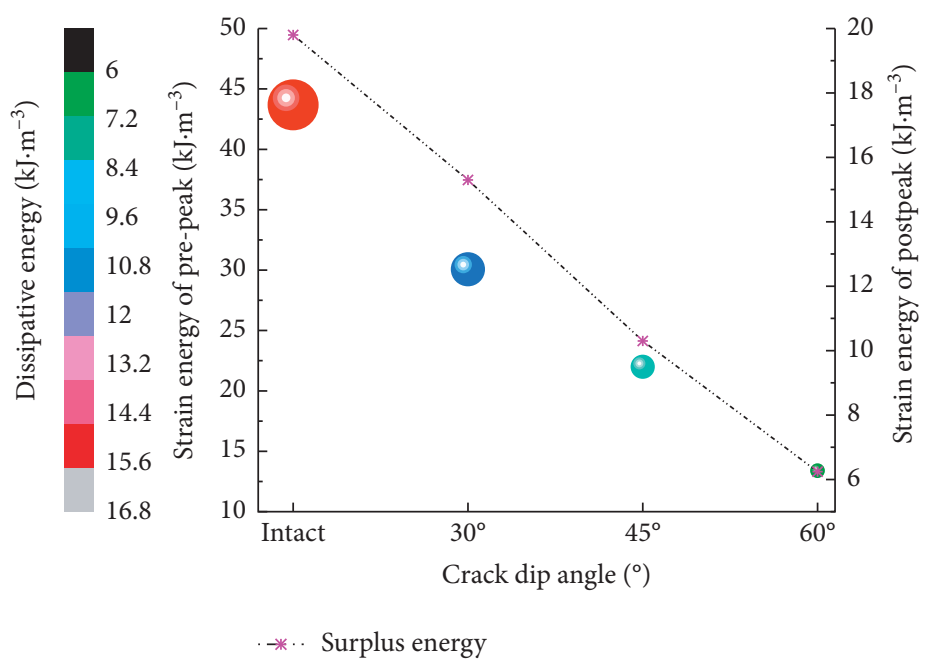

(a)

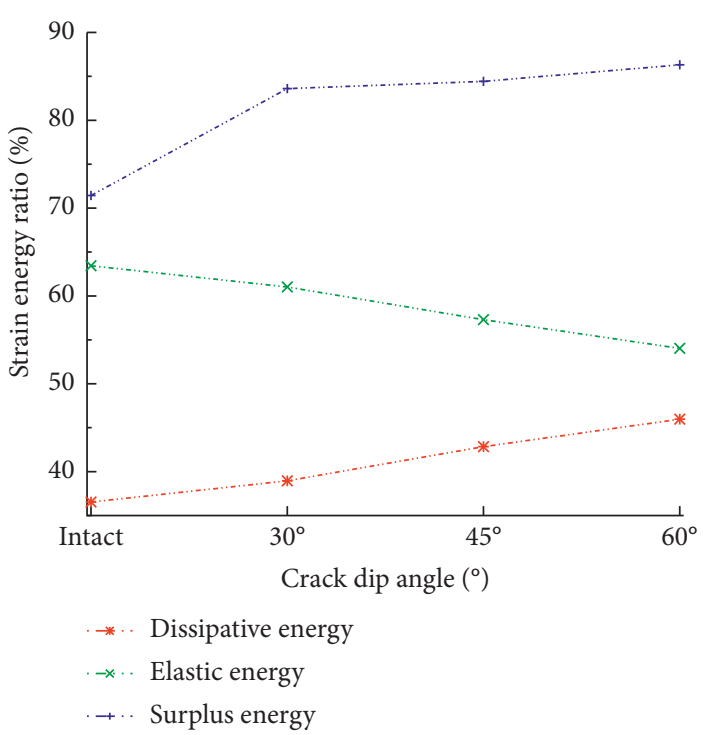

(b)

FIgURE 6: Curves depicting the relationship between the strain energy and precrack dip angle in typical intact and precracked rock specimens: (a) peak strain energy and (b) strain energy ratio (share).

the peak was mainly stored in the form of elastic energy. In contrast, only a small part of this energy was dissipated.

As the precrack dip angle increased, the peak elastic energy share before the peak decreased while that of the dissipative energy increased. This implies that, with an increase in the precrack dip angle, the damage accumulates more intensively at the precrack tips. As a result, cracks propagate more rapidly, and rock specimens become more susceptible to failure. The surplus energy is mainly spent on the ejection failure of rock specimens. As the precrack dip angle increases, the peak surplus energy drops while the peak surplus energy share is increased. This happens because the brittle failure of rock specimens is intensified, and the postpeak released energy drops at larger precrack dip angles. Consequently, the main part of the elastic energy accumulated at the precrack tips is converted into surplus energy. In other words, rock specimens acquire higher kinetic energy upon failure, which is accompanied by severe ejection of the chipped and fragmented rock specimens. Thus, the cracking sounds are emitted and recorded by the AE system.

The prepeak dissipative energy peak value shares increase at larger precrack dip angles. Therefore, rock specimens are more susceptible to failure. The peak surplus energy share increases and rock specimens are more susceptible to ejection failure. In actual roadway excavation and stoping of the coal mine working face, when large-scale and large-dip-angle defects (geological structures, such as faults and joints) are exposed, the following precautions should be taken. The fragmentation of the surrounding defective rock masses should be prevented to ensure the safe advance of the roadway and working face; energy variation near the defects should be carefully monitored; and other appropriate countermeasures should be adopted to reduce the structural impact hazards.

\section{Damage Evolution Analysis of Rock Specimens}

4.1. AE Energy Distribution during the Entire Process of Rock Specimen Loading. Figure 7 depicts the AE energy distribution characteristics during uniaxial loading in typical intact and precracked rock specimens. At the early loading stage, stresses generated in rock specimens are relatively small. The energy input into rock specimens is mostly consumed by the closure of the original cracks. There is little elastic energy stored in the rock specimens while shear stresses are concentrated to a lesser degree at the precrack tips. At this stage, few elastic waves are produced in rock specimens. With an increase in the load and stress in rock specimens, the energy input becomes converted into elastic stress waves. Shear stresses become more concentrated at the precrack tips. After the closure of the original cracks, new ones are formed at their tips, and more elastic waves are generated in the rock specimens. As the stress level further increases, rock specimens exhaust their ultimate ability of energy storage. The coalescence of microcracks occurs in rock specimens, and macroscopic fractures appear on the rock specimen surface, accompanied by a sudden rise in the $\mathrm{AE}$ energy characterized as the continuous type.

The occurrence of the first AE energy peak in intact and precracked rock specimens with dip angles of 30,45 , and $60^{\circ}$ was revealed after $153,101,73$, and $37 \mathrm{~s}$, respectively. The corresponding axial stresses were 38.9, 25.7, 18.6, and 9.4 MPa, respectively. The first macroscopic crack (corresponding to the first peaks of $\mathrm{AE}$ energy and ring-down count) has appeared earlier, and the axial stress level required for the fracture was reduced with the dip angle. This result confirms the fact that the presence of prefabricated cracks significantly accelerates the failure of rock specimens. 


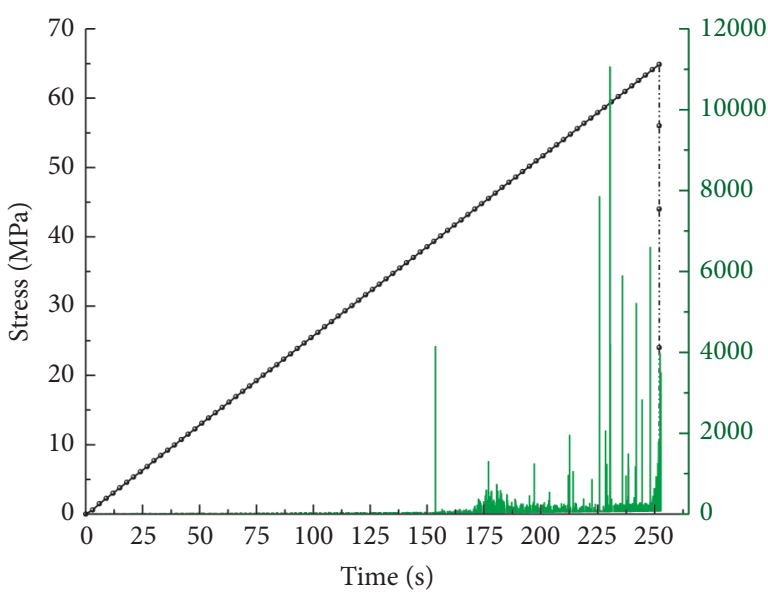

(a)

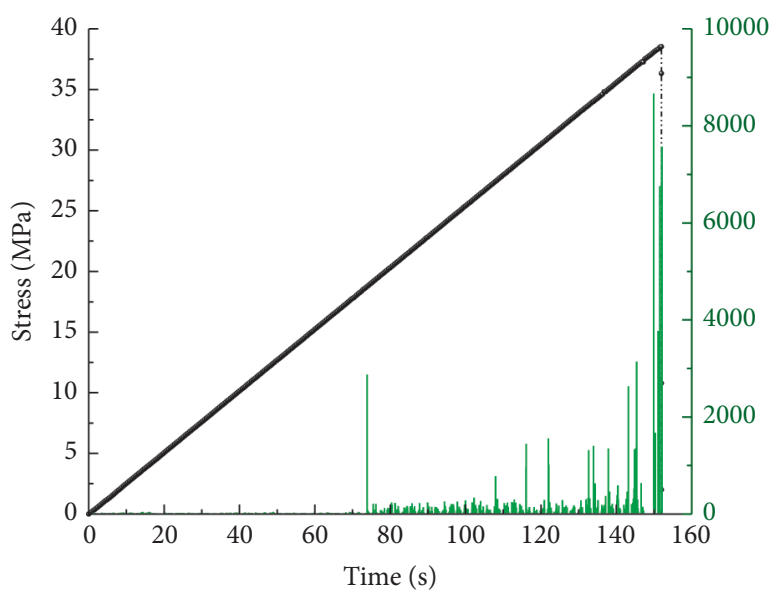

(c)

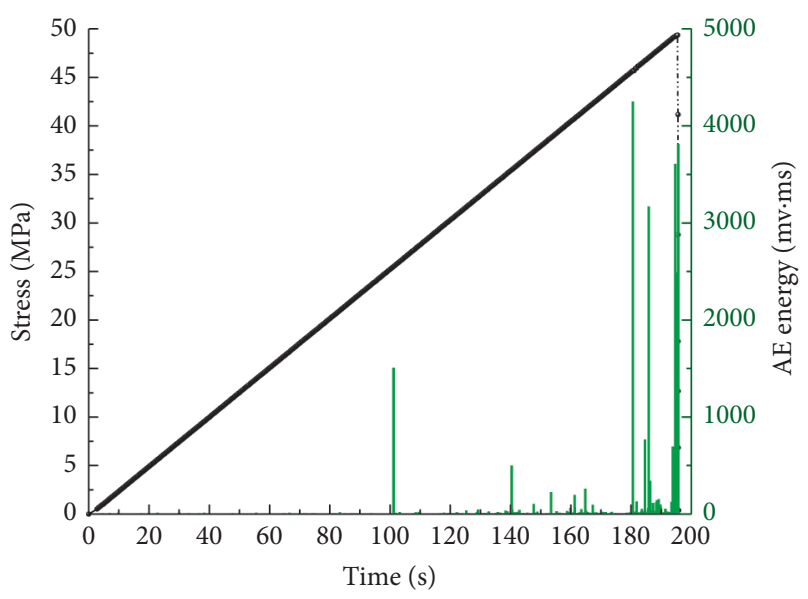

(b)

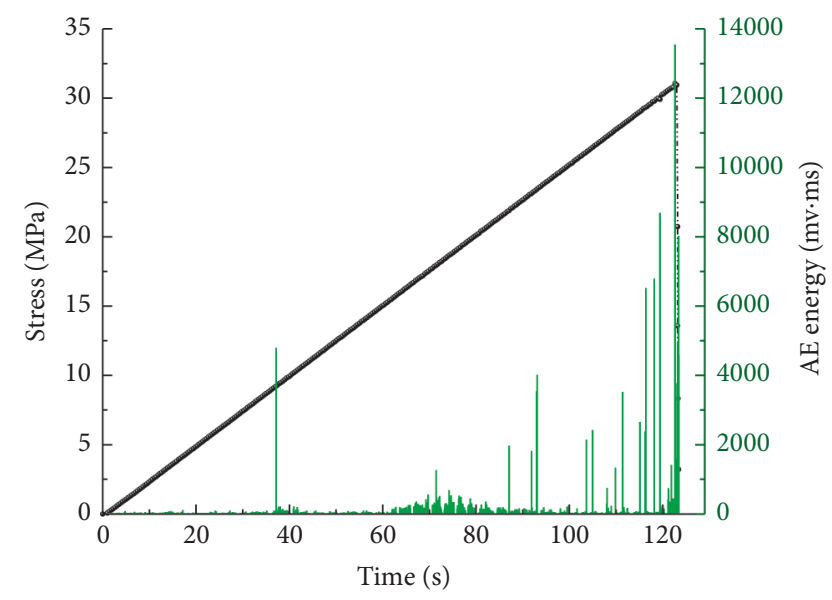

(d)

Figure 7: The AE energy evolution during the entire loading process of intact (a) and precracked rock specimens with a dip angle of $30^{\circ}$ (b), $45^{\circ}(\mathrm{c})$, and $60^{\circ}(\mathrm{d})$.

4.2. Characterization of Rock Specimen Damage by the AE Energy Parameters. The AE energy value is highly sensitive to the damage and fracture of rock specimens. It can intuitively reflect the initiation, propagation, and coalescence of cracks in rock specimens. Therefore, in this study, the AE energy was used as a characteristic parameter to reflect the damage evolution in intact and precracked rock specimens.

The equation of rock specimen damage evolution under uniaxial compression was elaborated based on the statistical damage theory:

$$
\sigma=E(1-D) \varepsilon_{1}
$$

where $\sigma$ is the axial stress, $\mathrm{MPa} E$ is the elastic modulus, $\mathrm{MPa}$; and $D$ is the damage factor, representing the ratio between the microcrack length and the size of microbodies in the rock specimen.

Assuming that the strength of microbodies in rock specimens obeys the Weibull distribution [28], the relationship between the damage factor and AE energy parameters can be expressed as follows:

$$
D=\frac{N_{\mathrm{t}}}{N_{\mathrm{a}}},
$$

where $N_{\mathrm{t}}$ and $N_{\mathrm{a}}$ are the cumulative AE energy values at the loading start and complete failure instants, respectively, $\mathrm{mv} \cdot \mathrm{ms}$.

In the triaxial compression test, rock specimens do not undergo complete failure due to the confining pressure, which contributes to their residual strength. However, in the uniaxial compression test, the rock specimens might still retain residual strength after the peak. The theoretical model depicting the relationship between the damage factor and AE parameters based on the Weibull distribution does not consider the residual strength after the failure of rock specimens under loading. Instead, it assumes that the complete failure of rock specimens occurs when $\varepsilon=\max \varepsilon$, i.e., $D=1$, whose condition is not realistic. Therefore, the adjustment coefficient $m$ is introduced and equation (8) is modified to the following form: 


$$
D=m \frac{N_{\mathrm{t}}}{N_{\mathrm{a}}} .
$$

By incorporating the residual strength, $m$ can be estimated as

$$
m=\frac{\sigma_{\mathrm{c}}-\sigma_{\mathrm{p}}}{\sigma_{\mathrm{c}}}
$$

where $\sigma_{\mathrm{p}}$ is the residual strength, $\mathrm{MPa}$.

By introducing formulas (9) and (10) into (7), the equation of the rock specimen damage evolution under uniaxial compression, characterized by the AE energy, is derived as follows:

$$
\sigma=E\left(1-\frac{\sigma_{\mathrm{c}}-\sigma_{\mathrm{p}}}{\sigma_{\mathrm{c}}} \frac{N_{\mathrm{t}}}{N_{\mathrm{a}}}\right) \varepsilon_{1}
$$

The normalization method was used to convert the damage variable characterized by the cumulative AE energy in typical intact and precracked rock specimens. Thus, the damage evolution process of rock specimens under uniaxial compression was obtained, as shown in Figure 8.

It can be observed that the damage evolved in both types of rock specimens follows a similar trend, which can be subdivided into three stages.

(A) The initial damage stage: At this stage, rock specimens exhibit low damage degree, and the damage variable is approximately zero. The reason is that it corresponds to the compaction stage and early elastic stage of the stress-strain curve. The energy input into rock specimens is mainly consumed by the closure of precracks. The bulk stress state of rock specimens is relatively uniform, without the formation or propagation of new cracks.

(B) The stable damage increase stage: At this stage, the rock specimen damage increases nonlinearly with a high variation rate. This happens because it corresponds to the middle and late elastic and early plastic stages of the stress-strain curve. At this time, the original cracks in rock specimens are closed. As the stress imposed by the test machine gradually increases, the original cracks further propagate after reaching the ultimate state while new cracks are formed and start to propagate.

(C) The accelerating damage increase stage. This stage, characterized by a sharp increase in rock specimen damage, is very short. The reason is that it corresponds to the middle and later plastic stage and residual deformation stage of the stress-strain curve. Microcracks in rock specimens propagate and coalesce rapidly, forming a crack network with the interpenetration of cracks. Thus, rock specimens undergo macroscopic failure.

The comparative analysis of the damage evolution processes in typical intact and precracked rock specimens revealed that an increase in the precrack dip angle reduced the initial damage stage duration. The damage accumulated

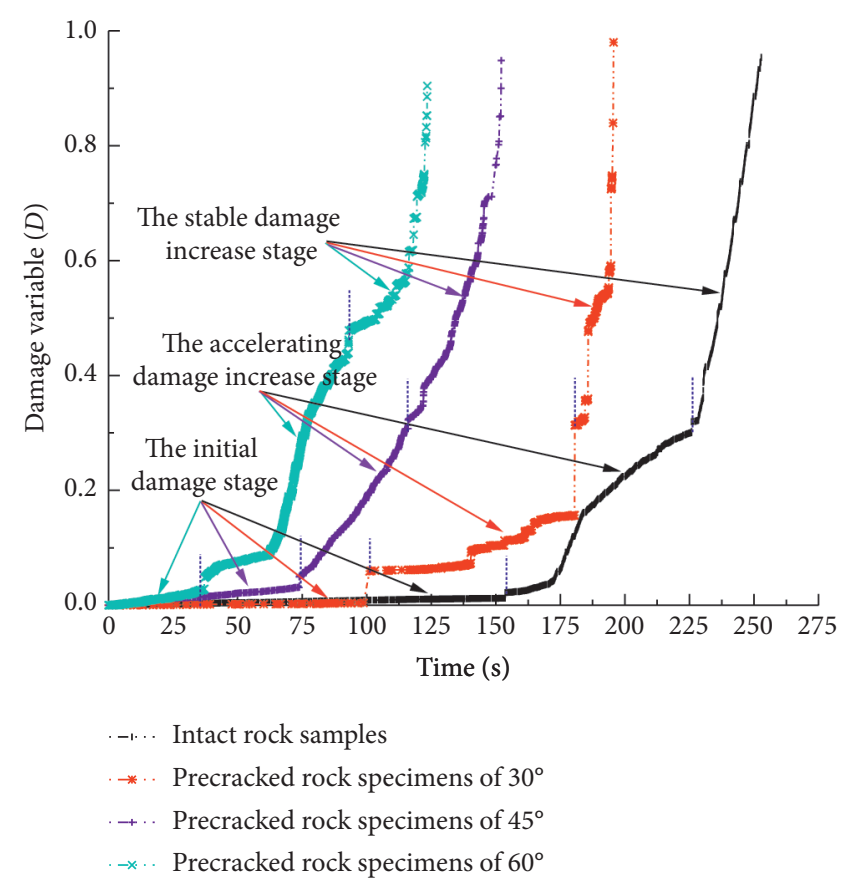

FIGURE 8: Damage evolution curves of typical intact and precracked rock specimens characterized by the AE energy.

more rapidly, promoting the evolution of rock specimens toward a "sudden instability."

4.3. Fracture Morphology of Rock Specimens. Figure 9 presents the macrofracture morphology and SEM images of fracture surfaces of intact and precracked rock specimens. In accordance with earlier findings [29], pure tensile wing cracks were generated in the intact rock specimens and propagated to their bottom. In rock specimens with the precrack dip angle of $30^{\circ}$, the formation of tensile wing cracks and shear antiwing cracks being nearly normal to the precracks was observed. In the rock specimens with a precrack dip angle of $45^{\circ}$, tensile-shear composite wing and antiwing cracks were nearly normal to the precracks, while and tensile-shear secondary cracks were nearly parallel to them. In the rock specimens with the precrack dip angle of $60^{\circ}$, shear wing and shear secondary cracks were nearly parallel to the precracks formed. In all the above cases, the formed cracks propagated to reach the roof and bottom of rock specimens.

As the precrack dip angle is increased, the fracture mode of rock specimens changed from the tensile and splitting one to shear and slip fracture. There was a certain consistency in the macrofracture morphology and mutual conversion between different strain energy forms in rock specimens. Larger precrack dip angles promoted the ultimate energy storage ability exhaustion and increased the shear stress concentration at the precrack tips. Therefore, precracked rock specimens underwent fast shear and slip failure.

The morphological features of the fracture surfaces of typical intact and precracked rock specimens were instrumental in determining the damage and failure evolution 

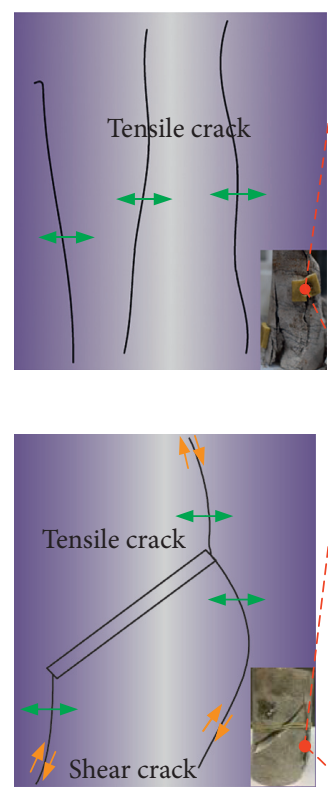

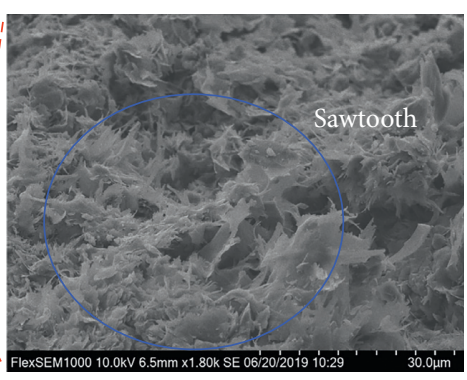

(a)

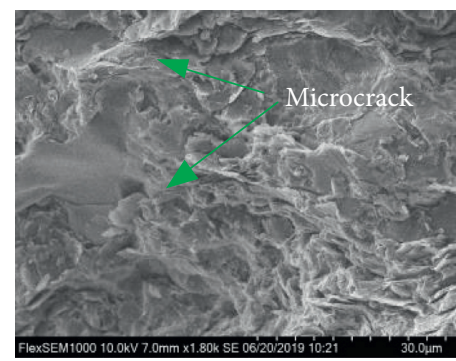

(c)
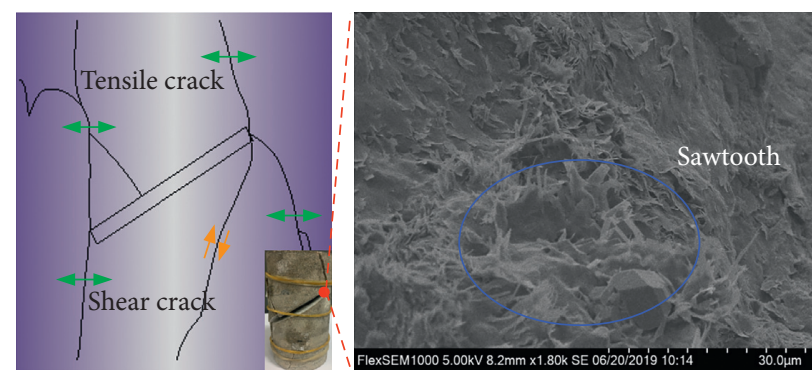

(b)
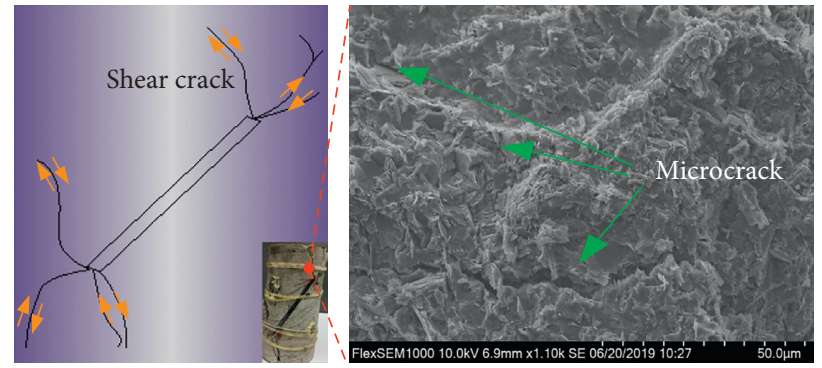

(d)

FIGURE 9: SEM images of fracture morphology and fracture surfaces of typical intact (a) and precracked rock specimens with a dip angle of $30^{\circ}(\mathrm{b}), 45^{\circ}(\mathrm{c})$, and $60^{\circ}(\mathrm{d})$.

patterns on the microscopic scale. The intact rock specimens had flat fracture surfaces with multiple sawtooth-like (jagged) structures. The latter structures could lock into and rub against each other, thus inhibiting the rock specimen's failure to a certain degree. As the precrack dip angle increased, sawtooth-like structures became smaller, and fracture surfaces became uneven, with developed microcracks. The above results confirm that larger precrack dip angles make specimens more susceptible to "sudden" failure, which is in concert with the damage evolution characteristics of rock specimens characterized by the AE energy.

During the uniaxial compression tests of rock specimens with small-scale prefabricated cracks $[15,30,31]$, their peak strength and strain increased with the prefabricated crack dip angle. Besides, the stress-strain curve became rightshifted, in contrast to the uniaxial compression test results for rock specimens with large-scale prefabricated cracks. The prepeak energy dissipation gradually increased in rock specimens with small-scale cracks while sudden energy dissipation occurred at the plastic stage in specimens with large-scale ones. Thus, large-scale inclined prefabricated cracks severely impaired the integrity of rock specimens. In the compression tests, microcracks were more developed in the rock specimens with large-scale inclined prefabricated cracks. The fracture of rock specimens occurred in the form of collapse.

\section{Conclusions}

The results obtained made it possible to draw the following conclusions.

(1) Rock specimens with inclined precracks exhibited alterations in the compressive strength and deformation features, as compared to intact ones. With an increase in the precrack dip angle, their fracture mode changed from the tensile and splitting one to shear and slip fracture.

(2) In precracked rock specimens, the energy storage at an accelerating rate was observed at the elastic deformation while rapid energy dissipation occurred at the plastic stage. Both the prepeak dissipative energy and postpeak surplus energy shares in the total energy increased with the precrack dip angle. This indicates higher kinetic energy for the ejection of rocks, causing rock specimen fragmentation. Meanwhile, the kinetic energy in intact rock specimens rose more gradually.

(3) Based on the derived damage evolution equation, the rock specimens' damage process was subdivided into (i) the initial damage stage, (ii) stable damage increase stage, and (iii) the accelerating damage increase stage. As the precrack dip angle increased, the first peak of AE energy occurred earlier, and the corresponding stress level provided by the test machine was reduced. The damage in rock specimens accumulated at an accelerating rate. The sawtooth-like structures on the fracture surface were less likely to lock into each other. The fracture surface became uneven, and microcracks gradually developed. As a result, the rock specimens were more susceptible to the "sudden" failure.

\section{Data Availability}

The data used for conducting classifications are available from the corresponding author authors upon request. 


\section{Conflicts of Interest}

The authors declare that they have no conflicts of interest.

\section{Acknowledgments}

The authors acknowledge the financial support for this work provided by the National Natural Science Foundation of China (Grant no. 51634007) and the Graduate Innovation Fund Project of Anhui University of Science and Technology of China (2019CX1003).

\section{References}

[1] H. P. Xie, F. Gao, and Y. Ju, "Research and development of rock mechanics in deep ground engineering," Chinese Journal of Rock Mechanics and Engineering, vol. 34, no. 11, pp. 2161-2178, 2015.

[2] L. Yuan, "Scientific conception of coal mine dust control and occupational safety," Journal of China Coal Society, vol. 45, no. 1, pp. 1-7, 2020.

[3] S.-Q. Yang and H.-W. Jing, "Strength failure and crack coalescence behavior of brittle sandstone samples containing a single fissure under uniaxial compression," International Journal of Fracture, vol. 168, no. 2, pp. 227-250, 2011.

[4] S.-Q. Yang, W.-L. Tian, Y.-H. Huang, P. G. Ranjith, and Y. Ju, "An Experimental and numerical study on cracking behavior of brittle sandstone containing two non-coplanar fissures under uniaxial compression," Rock Mechanics and Rock Engineering, vol. 49, no. 4, pp. 1497-1515, 2016.

[5] D. Li, E. Wang, X. Kong, M. Ali, and D. Wang, "Mechanical behaviors and acoustic emission fractal characteristics of coal specimens with a pre-existing flaw of various inclinations under uniaxial compression," International Journal of Rock Mechanics and Mining Sciences, vol. 116, pp. 38-51, 2019.

[6] T. X. Xue, R. S. Fu, Y. W. Chen, and Z. G. Shao, "Numerical simulation of large scale fault activity and it's seismological analogy," Progress in Geophysics, vol. 24, no. 5, pp. 1616-1626, 2009.

[7] Q. G. Yu, H. X. Zhang, W. N. Zhang, Y. J. Zhang, and G. Y. Zhang, "Different fault activation models in mining subsidence," Journal of China Coal Society, vol. 44, no. 9, pp. 2777-2786, 2019.

[8] Y. L. Tan, W. J. Guo, H. Q. Xin, T. B. Zhao, and F. H. Yu, "Key technology of rock burst monitoring and control in deep coal mining," Journal of China Coal Society, vol. 44, no. 1, pp. 160-172, 2019.

[9] T.-b. Zhao, W.-y. Guo, Y.-l. Tan, Y.-c. Yin, L.-s. Cai, and J.-f. Pan, "Case studies of rock bursts under complicated geological conditions during multi-seam mining at a depth of 800 m," Rock Mechanics and Rock Engineering, vol. 51, no. 5, pp. 1539-1564, 2018.

[10] G. Cheng, L. Li, W. Zhu et al., "Microseismic investigation of mining-induced brittle fault activation in a chinese coal mine," International Journal of Rock Mechanics and Mining Sciences, vol. 123, Article ID 104096, 2019.

[11] O. Dorostkar and J. Carmeliet, "Potential energy as metric for understanding stick-slip dynamics in sheared granular fault gouge: a coupled CFD-DEM study," Rock Mechanics and Rock Engineering, vol. 51, no. 10, pp. 3281-3294, 2018.

[12] K. Zhao, X. Yu, Y. Zhou, Q. Wang, J. Wang, and J. Hao, "Energy evolution of brittle granite under different loading rates," International Journal of Rock Mechanics and Mining Sciences, vol. 132, Article ID 104392, 2020.
[13] Z. Zhang, M. Deng, J. Bai, X. Yu, Q. Wu, and L. Jiang, "Strain energy evolution and conversion under triaxial unloading confining pressure tests due to gob-side entry retained," International Journal of Rock Mechanics and Mining Sciences, vol. 126, Article ID 104184, 2020.

[14] L. Yang, F. Q. Gao, X. Q. Wang, and J. Z. Li, "Energy evolution law and failure mechanism of coal-rock combined specimen," Journal of China Coal Society, vol. 44, no. 12, pp. 2217-2224, 2019.

[15] G. L. Wang, L. Zhang, M. Xu, Z. Y. Liang, and B. L. Ran, "Energy damage evolution mechanism of non-across jointed rock mass under uniaxial compression," Chinese Journal of Geotechnical Engineering, vol. 41, no. 4, pp. 639-647, 2019.

[16] J. F. Jin, H. B. Zhong, Y. Wu, Z. Q. Guo, and X. J. Zhou, "Method selection for defining damage variable of rock subjected to static loadings and cyclic impacts," Nonferrous Metals Science and Engineering, vol. 4, no. 4, pp. 85-90, 2013.

[17] H. P. Xie, Y. Ju, and Y. L. Dong, "Research on plastic modulus method for classical damage mechanical definition," Mechanical and Practice, vol. 19, no. 2, pp. 2-6, 1997.

[18] Z. H. Guo, X. R. Liu, B. X. Liu, Z. L. Shu, and Y. Fu, "Experiment study of rock damage deformation characteristics based on plastic volumetric strain analysis," Journal of Experimental Mechanics, vol. 25, no. 3, pp. 223-298, 2010.

[19] Q. S. Zhang, G. S. Yang, and J. X. Ren, "New study of damage variable and constitutive equation of rock," Chinese Journal of Rock Mechanics and Engineering, vol. 22, no. 1, pp. 30-34, 2003.

[20] K. Zhao, H. Y. Zhao, and Q. Y. Jia, "An analysis of rock burst fracture micromorphology and study of its mechanism," Explosion and Shock Waves, vol. 35, no. 6, pp. 913-916, 2015.

[21] X. S. Liu, J. G. Ning, Y. L. Tan, and Q. H. Gu, "Damage constitutive model based on energy dissipation for intact rock subjected to cyclic loading," International Journal of Rock Mechanics and Mining Sciences, vol. 85, pp. 27-32, 2016.

[22] Z. Jia, H. Xie, R. Zhang et al., "Acoustic emission characteristics and damage evolution of coal at different depths under triaxial compression," Rock Mechanics and Rock Engineering, vol. 53, no. 5, pp. 2063-2076, 2020.

[23] D. Huang, R. Q. Huang, and Y. X. Zhang, "Experimental investigations on static loading rate effects on mechanical properties and energy mechanism of coarse crystal grain marble under uniaxial compression," Chinese Journal of Rock Mechanics and Engineering, vol. 31, no. 2, pp. 245-255, 2012.

[24] R. Solecki and R. J. Conant, Advanced Mechanics of Materials, Oxford University Press, London, UK, 2003.

[25] H. Xie, L. Li, R. Peng, and Y. Ju, "Energy analysis and criteria for structural failure of rocks," Journal of Rock Mechanics and Geotechnical Engineering, vol. 1, no. 1, pp. 11-20, 2009.

[26] R. Peng, Y. Ju, J. G. Wang, H. Xie, F. Gao, and L. Mao, “Energy dissipation and release during coal failure under conventional triaxial compression," Rock Mechanics and Rock Engineering, vol. 48, no. 2, pp. 509-526, 2015.

[27] G. Liu, F. K. Xiao, and T. Qin, "Rock mechanics characteristics and acoustic emission rule under small-size effect," Chinese Journal of Rock Mechanics and Engineering, vol. 37, no. S2, pp. 3905-3917, 2018.

[28] X. Y. Wang, H. W. Zhou, J. C. Zhong, L. Zhang, and C. S. Wang, "Study on energy evolution and permeability characteristics of damage of deep coal under triaxial cyclic loading and unloading conditions," Chinese Journal of Rock Mechanics and Engineering, vol. 37, no. 12, pp. 2676-2684, 2018. 
[29] C. A. Tang, P. Lin, R. H. C. Wong, and K. T. Chau, "Analysis of crack coalescence in rock-like materials containing three flaws-part II: numerical approach," International Journal of Rock Mechanics and Mining Sciences, vol. 38, no. 7, pp. 925-939, 2001.

[30] Q. F. Guo, X. Wu, M. F. Cai, F. H. Ren, and J. L. Pan, "Crack initiation mechanism of pre-existing cracked granite," Journal of China Coal Society, vol. 44, no. S2, pp. 476-483, 2019.

[31] L. W. Liu, H. B. Li, X. F. Li, and R. J. Wu, "Full-field strain evolution and characteristic stress levels of rocks containing a single pre-existing flaw under uniaxial compression," Bulletin of Engineering Geology and the Environment, vol. 79, no. 6, pp. 3145-3161, 2020. 